\title{
Factors Associated with Student Enrollment, Completion, and Dropout of Massive Open Online Courses in the Sultanate of Oman
}

\author{
Vinu Sherimon* \\ Department of IT, University of Technology and Applied Sciences, Muscat, \\ Sultanate of Oman \\ http://orcid.org/0000-0003-4923-2841 \\ P. C. Sherimon \\ Faculty of Computer Studies, Arab Open University, \\ Muscat, Sultanate of Oman \\ http://orcid.org/0000-0001-6912-1407 \\ Leena Francis \\ Department of Science, Indian School Al Seeb, Muscat, Sultanate of Oman \\ http://orcid.org/0000-0001-8691-1582

\section{Disha Devassy} \\ Faculty of Computer Studies, Arab Open University, Riyadh, Kingdom of Saudi Arabia \\ http://orcid.org/0000-0003-4954-6357

\section{Teresa K. George} \\ Department of IT, the University of Technology and Applied Sciences, Muscat, \\ Sultanate of Oman \\ http:// orcid.org/0000-0001-6669-7478
}

\begin{abstract}
This research aims to investigate the elements that influence learners' enrollment in, completion of and dropout from Massive Open Online Courses (MOOCs). MOOCs attract a vast number of participants, with enrollments growing at an unprecedented rate; however, only a small number of students who enroll, complete their study. In this research, data were collected from 79 participants using an online survey. Professional growth, flexible time, free of charge, and the opportunity to obtain certification were recognized as the four main factors that directly influenced student enrollment in MOOCs. The motivational variables revealed in this study that led to the effective completion of MOOCs included good-quality course videos,
\end{abstract}

\footnotetext{
*Corresponding author: Vinu Sherimon; Email: vinusherimon@yahoo.com
} 
straightforward and clear tutor instructions, good course delivery, and useful instructor feedback, among others. The most prevalent reasons for dropout included failure to fulfil the deadline, the instructor's vocabulary, challenging assignments, and difficulty in grasping the course content. The findings of this study can provide educators and decision-makers with the information they need to better understand the factors that influence MOOC student enrollment, completion, and dropout rates, as well as relevant actions to improve the success rates of MOOC.

Keywords: learner commitment; self-learning; MOOC; MOOC satisfaction; MOOC dropout; learner motivation

\section{Introduction}

As a result of the extensive usage of information and communication technologies (ICTs), the pedagogical model has shifted in the twenty-first century and the advancement of ICT has meant that open, online, and flexible learning has moved from the periphery of standard education to the foreground (Kumar \& Kumar, 2020). Massive Open Online Courses (MOOCs), a modern endeavor that is attracting academic and industry attention, are a continuation of the open learning movement (Kumar \& Kumar, 2020). Early MOOCs frequently underscored open-access highlights, for example, open permitting of content, construction and learning objectives, so as to advance the reuse and remixing of assets. Some more recent MOOCs (Extended MOOCs) utilize close licenses for their course materials while keeping up with free access for understudies. They are a fast-growing style of higher education that has the potential to expand access to a global teaching and educational materials beyond social and geographical restrictions (Hone \& El Said, 2016). MOOC providers like Coursera, Udacity, and edX team up with world-class universities such as MIT, Stanford, and Harvard and offer online courses for free or at a low cost (Kumar \& Kumar, 2020). These courses provide an excellent opportunity for students from developing countries who would otherwise be unable to afford tuition fees to attend courses at such world-class universities.

In MOOCs, learners' dedication and learning processes are limited by the lack of a teacher. As a result, the efficiency of MOOCs is determined by to what extent participants control their own learning. Due to the lack of direct learnerinstructor contacts, course design elements have a significant impact on learners' self-directed study and dedication. Furthermore, despite the potential and excitement surrounding MOOCs, retention rates are generally very limited; the MOOC completion rate is less than $10 \%$ (Alraimi et al., 2015).

Much research has been undertaken to determine the factors that contribute to MOOC completion; however, the results vary. This study investigates the experiences of learners from the Sultanate of Oman with MOOCs and focuses specifically on the reasons of enrollment, and factors that increase both their satisfaction with MOOCs and dropout. This study adds to the corpus of knowledge on the subject of MOOC learner engagement and motivation and its findings can enable MOOC providers to encourage more students to take 
MOOCs, boost their engagement, and improve their learning outcomes as well as serve as the base of any market study by future MOOC providers in Oman.

\section{Research questions}

RQ1: What factors motivate a learner to enroll in MOOC?

RQ2: What motivates a learner to complete MOOC?

RQ3: What are the reasons of dropping out of MOOC?

RQ4: What are the strengths and limitations of MOOC?

\section{Objectives}

1. To study the factors that drives a learner to enroll in MOOC.

2. To review the factors that contribute to the successful completion of MOOC.

3. To study the factors that drives a learner to drop out of MOOC.

4. To study the strengths and limitations of MOOC.

In this article, the researcher aims to address the elements that drive learners to enroll in and successfully finish a MOOC, as well as the reasons that cause learners to quit the course and both the strengths and limitations of MOOC.

\section{Literature review}

\subsection{Factors that drive a learner to enroll in MOOC}

According to Jais, Chen, Rahim, and Din (2019), postgraduate students opt to take MOOCs offered by universities with a strong reputation, while other motivational factors reported by this research include the desire to learn and a subject that is not offered at other institutions.

The key motivations reported by participants in two MOOCs were investigated by Milligan and Littlejohn (2017) who found that respondents in both MOOCs shared a similar pattern of major motivations, with them citing potential benefits to their present or future jobs, thereby expanding their expertise to be more effective at work, as well as more generic comments indicating casual interest in the topic or a simple wish to study. Professionals considered MOOC study as beneficial in equipping them for new positions and career advancement. while students commented that MOOC studies supplemented their existing education.

Petronzi and Hadi (2016) looked at open feedback from students that were related to their course engagement objectives in a dementia course. Eight important topics emerged from the thematic analysis, all of which were related to involvement and the broader benefits of course participation, as well as professional and educational growth. These were to enhance the skills and to apply in the workplace, for obtaining general knowledge about dementia, to prepare for a better career/education, for additional information, other personal reasons, professional development, for refreshing the knowledge, and to understand the attitude toward dementia by different countries. 


\subsection{Factors that contribute to attaining the satisfaction that leads to the completion of a MOOC}

Based on the D\&M IS Success Model, Albelbisi et al. (2021) examined the effect of quality antecedents on learners' happiness with MOOCs. By investigating the links between quality factors (i.e., system quality, information quality, service quality) and satisfaction, the study highlighted the critical importance of satisfaction in the MOOC setting. The authors found that system quality has a substantial impact on satisfaction, implying that the greater the system quality of MOOCs in terms of ease of use, ease of learning and operating MOOCs, and flexibility of MOOCs, the more likely learners are to be satisfied with MOOC use. However, the study's results revealed that characteristics such as information quality and service quality were not justified.

Knöös and Rääf (2021) sought to investigate how MOOC students behaved, the goal being to determine which characteristics inspire students and whether these elements distinguish between students who complete a course and those who drop out. Eighteen factors were found to stay motivated during the studies: content, the mode of delivery, self-discipline, just for fun, certificates, personal development, knowledge, career, time, assessments, interaction, instructor, reality, structure, external material, cost, community, and degree of difficulty.

In a MOOC environment, a lack of instructor presence may obstruct learners' dedication and learning processes (Kim et al., 2021). Using survey responses from 664 learners, Kim et al. (2021) evaluated the links between MOOC design features, learner commitment, self-directed learning, and future learning aspirations. The findings indicated that the transactional distance between learners and content was linked to students' self-directed learning.

In their study, Kumar and Kumar (2020) aimed to figure out how satisfied learners were with massive open online courses (MOOCs) by investigating the elements that influence learners' satisfaction with MOOCs, including course delivery, course assessment, and course assistance. Course assessment, course content, and course delivery were all demonstrated to have a substantial impact on overall satisfaction with MOOCs; however, the influence of course support on overall satisfaction was not determined to be significant.

Research by Bingol et al. (2020) explored the elements that influence course completion and success from the perspective of participants in a Massive Open Online Courses system in Turkey. According to the participants, course planning (course structure, design, syllabus, clarity, etc.), was the most important factor in their MOOC success. In addition, personal characteristics such as interest, willingness, desire to earn a certificate, etc., also had an impact on participants' achievement. Also, it was widely stated that the subject matter competence and teaching style of the instructors had an impact on the participants' accomplishments.

(Zhang et al. (2019) examined the extent to which several factors impact the completion of a Massive Open Online Course. And study found the motivational factors for enrolling in MOOC as friends, professors, institution, 
personal interest, new job, current job, academic program, connect with others, and earning the certificate.

Hone and El Said (2016) presented the results of a survey of 379 university students in Cairo who were motivated to attend a MOOC of their choosing as part of their personal growth. The research reported that the completion rates did not differ significantly by gender, study level, or MOOC platform. MOOC Course Material was found to be a major predictor of MOOC retention in a postMOOC survey of students' impressions, with the link moderated by the effect of content on the course's perceived effectiveness. The amount of time spent interacting with the MOOC lecturer was also determined to be significant. Another study by Shrader et al. (2016) listed engagement, cooperation, motivation, network opportunities, pedagogy, content, assessment, usability, technology, and learner support as characteristics that influence MOOC learner satisfaction. From August 2012 through December 2013, this research analysed activity patterns, participant demographics, and levels of satisfaction in numerous MOOC offers at the University of Illinois at Urbana-Champaign.

\subsection{Factors that drive a learner to drop out of a MOOC}

MOOCs have high dropout rates, with just a tiny fraction of students finishing the courses they enrolled in.

The major goal of research by Panagiotakopoulos et al. (2021) was to use a variety of well-known, cutting-edge supervised machine learning techniques to predict both student success and early student dropout in a MOOC. Results indicate that random forest (RF) excelled in terms of accuracy, sensitivity, and Cohen's kappa coefficient. Based on data obtained during the first week of the course, the experimental results demonstrate that accuracy exceeded 96\%, allowing for effective intervention tactics and support measures.

According to Knöös and Rääf )2021), nine de-motivating variables that contribute to a learner not finishing a course are: too difficult, too much work, lack of time, not improve $\mathrm{CV}$, not an interesting course, lack of self-discipline, not a requirement, not good delivery and low quality of video material. The participants commented that these factors contributed to the learners' failure to complete a course.

The role of motivational attitudes in finishing an open online course was investigated by Moore and Wang (2021) and students' performance was shown to be highly related to their educational background, gender, and motivation. Additionally, students with inherent motivating attitudes outperformed students with extrinsic motivational attitudes, and females outperformed males. According to Rawat et al. (2021), the course material, the time of the course delivery, and a student's attendance to course activities, as well as the length of the course, all had a role in the MOOC dropout trend.

The fundamental elements and potential causal links responsible for the high dropout rate in MOOCs were identified using a multiple-criteria decisionmaking process by Aldowah et al. (2020) who revealed twelve indicators connected to students dropping out of online courses, divided across four 
components. Academic skills and talents, previous experience, course design, feedback, social presence, and social support were identified as six primary characteristics that directly influenced student dropout in MOOCs. Other characteristics like interaction, course difficulty and time, dedication, motivation, and family/work conditions were discovered to play a minor influence in student dropout in the study.

\subsection{Strengths and limitations of MOOC}

Several MOOC advantages are reported by Srikanth (2020). Availability of free courses, access to courses taught by professors at prestigious universities, a wide range of courses, tracking facility to understand the performance of students, and interaction with professors and students from all over the world, which advances instructional practices and knowledge sharing. The report also includes the drawbacks. Non-availability of customized course content or oneon-one tutoring, the high challenge to keep track of all the students' assignments and activities, non-accessibility of MOOCs to students with special needs or who have a poor Internet connection, language-barriers, non-replacement of MOOC as a credit-earning course at colleges, etc. are some of them (Srikanth 2020)).

According to (Bates, 2015), MOOCs provide free access to high-quality content from some of the world's greatest universities to anybody with a computer and Internet access. In his book, "Teaching in a Digital Age", he states that MOOCs are useful for building basic conceptual learning and for forming massive online social networks of interest. By promoting their expertise and excellence in certain scholarly areas public, these universities have been able to expand their brand and prestige (Bates, 2015). Major weaknesses include mainly two factors MOOCs are expensive to create and ownership or time constraints may impede the re-use of MOOC materials as open educational tools (Bates, 2015).

\section{Research Methodology}

A descriptive research design is followed in this research. Descriptive research is a type of quantitative study that aims to collect measurable data in order to do statistical analysis on a population sample. The population of the research is identified as learners of different educational institutions in Oman. Students, faculty, and staff from few selected institutions in the Sultanate of Oman participated in the survey. The survey had a total of 79 participants.

This study used the convenience sampling approach, which is a nonprobabilistic sampling strategy. Convenience sampling helps the researcher to acquire fundamental facts and patterns about his research without the hassles of using a randomized sample. A self-developed questionnaire was utilized to acquire the necessary responses from participants. The questionnaire link was distributed to the participants through email. The questionnaire was divided into two pieces (Part I and Part II). Part I of the survey asked respondents about their personal information, while Part II asked about their reasons for enrolling in a MOOC, their experience with MOOCs, their preferences for MOOCs, their strengths, and their limitations. The completed questionnaires were examined using descriptive statistics such as frequency and percentages. Microsoft Excel was used to analyse the data. 


\section{Results}

\subsection{Analysis of Demographic data}

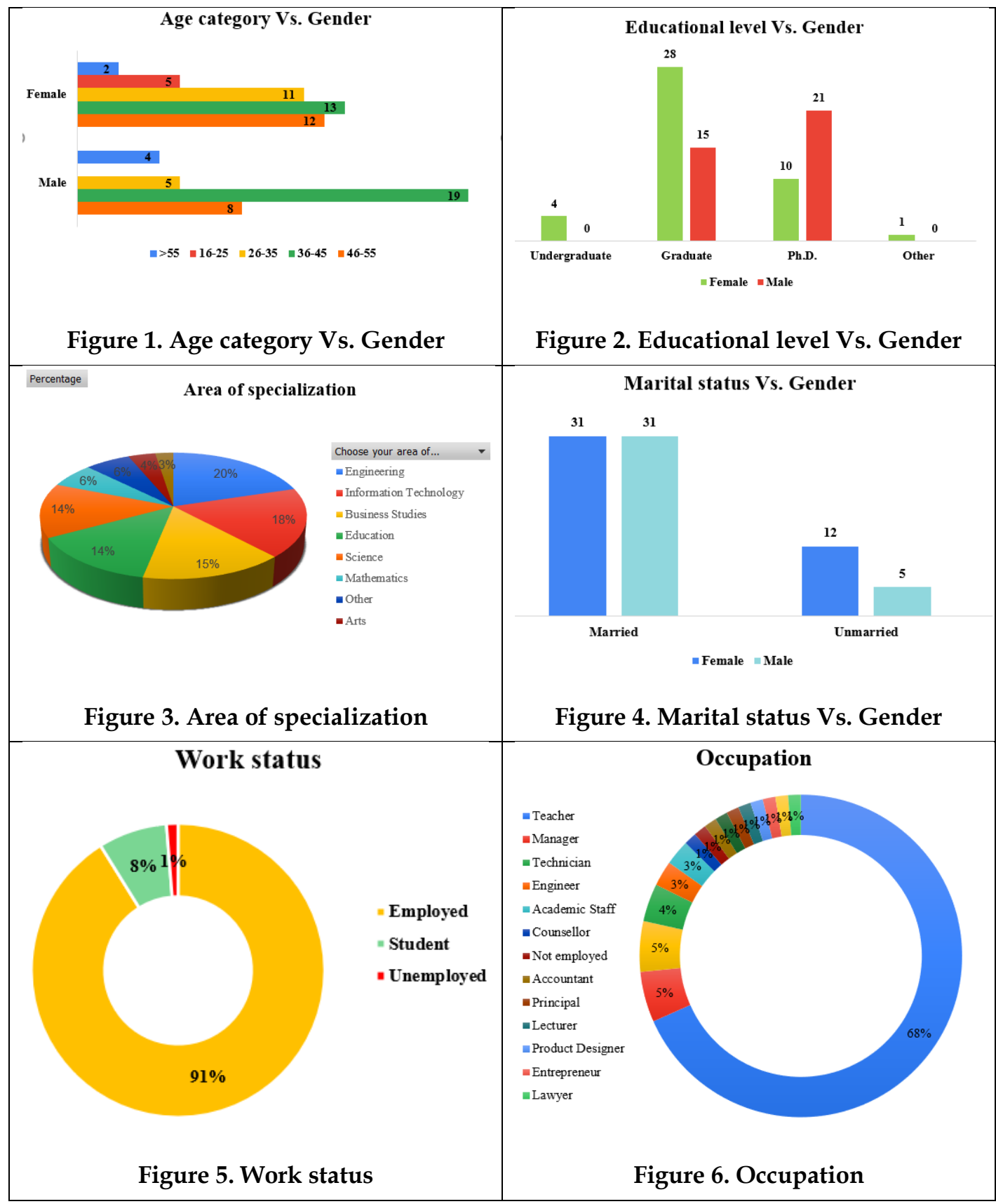

Figures 1-6 give a quick overview of the participants' characteristics. Female participants $(54 \%)$ outnumber male participants $(46 \%)$ in this study. Figure 1 shows the analysis of the age category and gender of the participants. In the female's category, $30 \%$ of the participants belong to the age category $36-45,28 \%$ belongs to the $46-55$ age category, $25 \%$ of the participants belongs to the age category $26-35,12 \%$ belongs to $16-25$ age category and $5 \%$ belongs to the age category $>55$ years. Figure 2 shows the analysis of the educational level/ qualification of the study participants. In the Undergraduate category, $100 \%$ of the participants were females. $65 \%$ of the females and $35 \%$ of the males are 
graduates, $32 \%$ of the females and $68 \%$ of the males hold Ph.D. And, in Other category, $100 \%$ of the participants were females.

The area of specialization of the participants is given in Figure 3. The highest number of participants were from Engineering specialization (20\%), followed by Information Technology (18\%), Business Studies (15\%), Education (14\%), Science $(14 \%)$, Mathematics (6\%), Others (6\%), Arts (4\%) and Literature (3\%). Figure 4 presents the analysis of the marital status of the participants. $78 \%$ of the participants were married and the remaining $22 \%$ were unmarried. Among the married participants, $50 \%$ were males and 50\% were females. Among the unmarried, $71 \%$ were females and $29 \%$ were males.

The majority of the participants were employed (91\%) as shown in Figure 5. 8\% were students and 1\% were unemployed. $68 \%$ of the study participants belong to the category Teacher, followed by Manager (5\%), Technician $(4 \%)$, Engineer (3\%), Academic Staff (3\%), Counsellor (1\%), Accountant (1\%), HR (1\%), Principal $(1 \%)$, Lecturer $(1 \%)$, Product Designer $(1 \%)$, Entrepreneur $(1 \%)$, Head of Department $(1 \%)$, Lawyer $(1 \%)$, Un-employed $(1 \%)$, and others $(5 \%)$ as given in Figure 6.

\subsection{Analysis of literature Review}

4.2.1 RQ1: What factors motivate a learner to enroll in MOOC?

This question seeks to find out how MOOCs are being utilized today as well as why they are adopted. Respondents were asked to indicate the motivational factors that led them to enroll in MOOCs. They were given different options with multiple answers to select. Figure 7 shows the different motivational factors that led to MOOC enrollment. Professional development resulted as the top 1 motivational factor with $26 \%$ followed by Flexible timing $(20 \%)$, Free $(17 \%)$, To get certification (14\%), Affordable (12\%), No prerequisite is required $(7 \%)$, Others (3\%) and Promotion (1\%).

The gender-wise analysis of the motivational factors is given in Figure 8. $43 \%$ of the males and $57 \%$ of females suggested that they enrolled in MOOC because of the 'Free' option. $37 \%$ of the males and $63 \%$ of females chose the motivational factor 'Affordable". $17 \%$ of the males and $83 \%$ of females chose the motivational factor 'No prerequisite is required". The motivational factor 'Flexible Timing' was chosen by $44 \%$ of males and $56 \%$ of females. The motivational reason "To obtain certification" was chosen by $27 \%$ of males and $73 \%$ of females. Females were the only ones who chose the motivational factor "Promotion." $40 \%$ of the males and $60 \%$ of females chose the motivational factor' Professional Development". The motivational element 'Others' was indicated by $20 \%$ of males and $80 \%$ of females. 


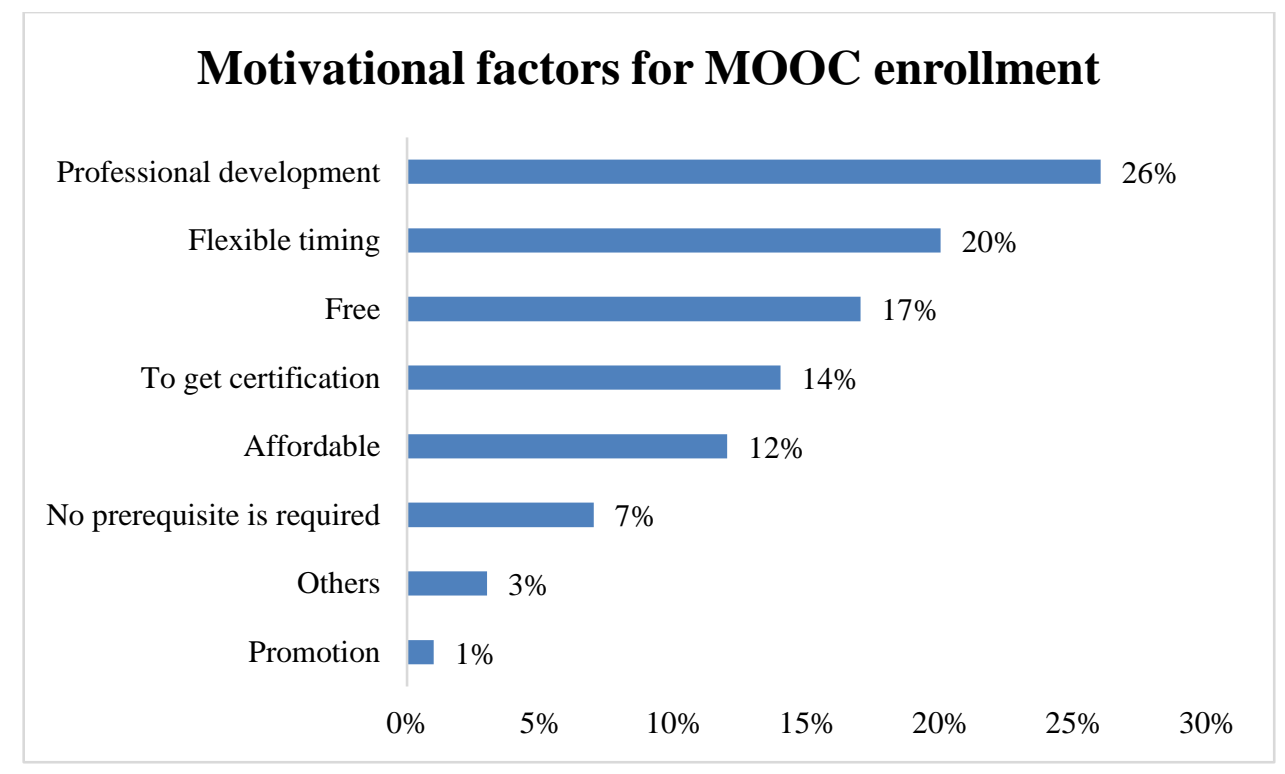

Figure 7. Motivational factors for MOOC enrolment

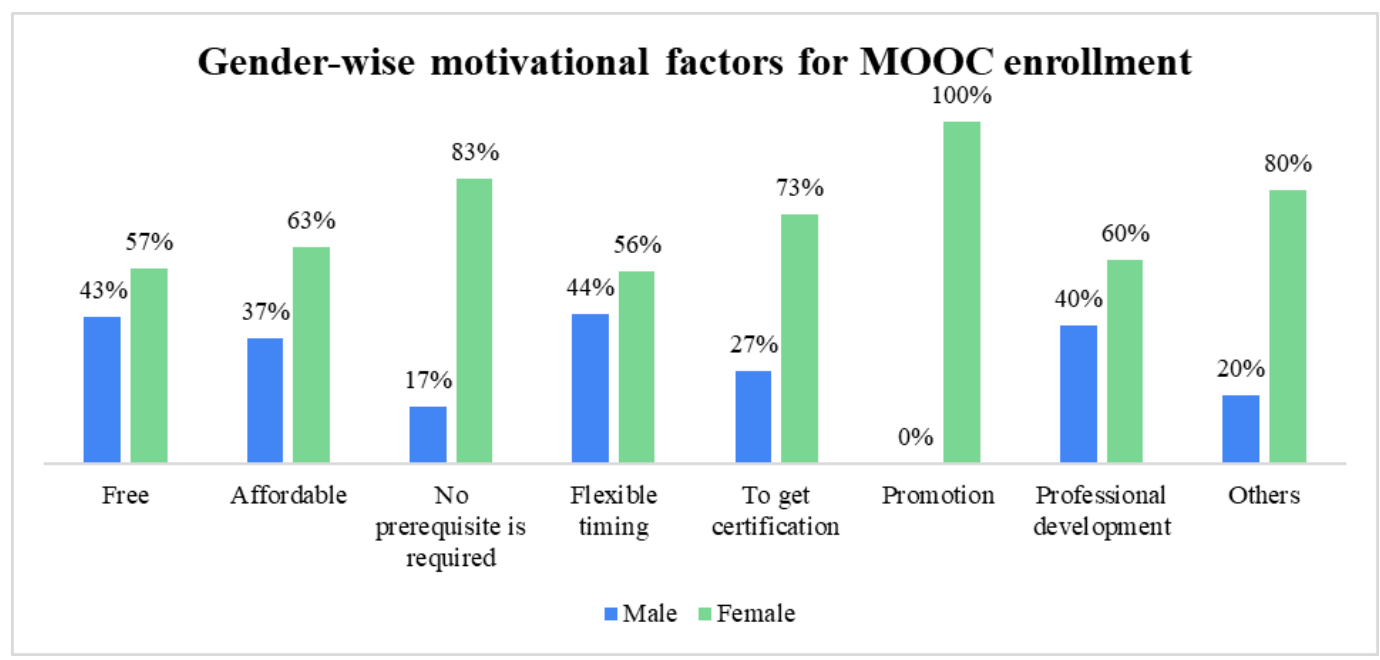

Figure 8. Gender-wise motivational factors for MOOC enrolment

\subsubsection{RQ2: What motivates a learner to complete MOOC?}

In a recent Stanford study, different engagement levels of learners from three different MOOCs were examined and four types of learners were identified: participants who completed the course audited the course, disengaged, and sampled the course (Yesil, 2014). Figure 9 presents the motivational factors that enable a learner to complete MOOC. Participants were asked to indicate how strongly they agreed with each item. As per Figure 9(a), 10\% of the participants strongly agreed that the direction of the instructor was legible and easy to follow, $48 \%$ agree, $41 \%$ neutral and 1\% strongly disagree. Figure 9 (b) presents the results of the responsiveness of the instructor. $8 \%$ of the participants strongly agreed that the instructor was responsive to the queries, $37 \%$ agree, $52 \%$ were neutral, and $4 \%$ strongly disagree. As per Figure 9 (c), $5 \%$ of the participants 
strongly agreed that the instructor provided helpful and timely feedback, 38\% agree, 53\% neutral and 4\% strongly disagree. Figure 9 (d) presents the results of the opinion on the duration of videos. $10 \%$ of the participants strongly agreed that the duration of the videos was appropriate, $47 \%$ agree, $37 \%$ were neutral, $4 \%$ disagree and 3\% strongly disagree. Figure 9 (e) presents the results of the opinion on the quality of the videos. $15 \%$ of the participants strongly agreed that the quality of the videos was excellent, $44 \%$ agree, 37\% were neutral, $1 \%$ disagree and 3\% strongly disagree. Figure 9 (f) presents the results related to effective communication of the course content. $14 \%$ of the participants strongly agreed that the course content was communicated effectively, $44 \%$ agree, $37 \%$ were neutral, $1 \%$ disagree and $4 \%$ strongly disagree.

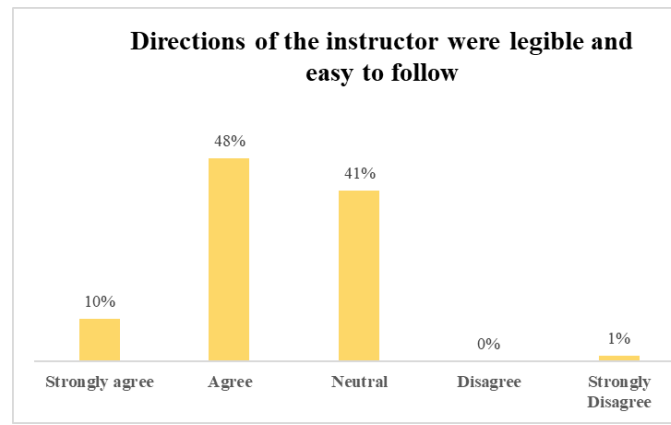

(a)

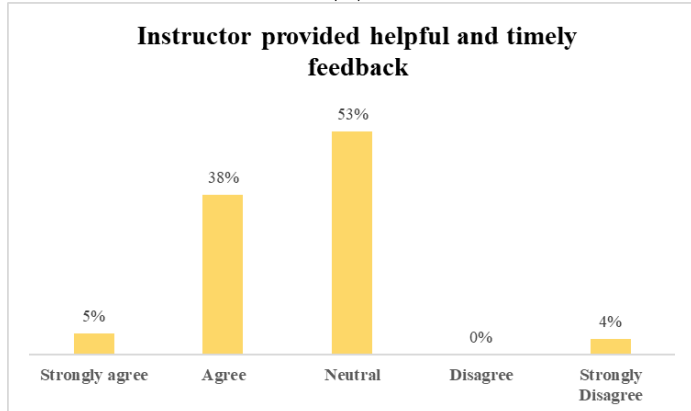

(c)

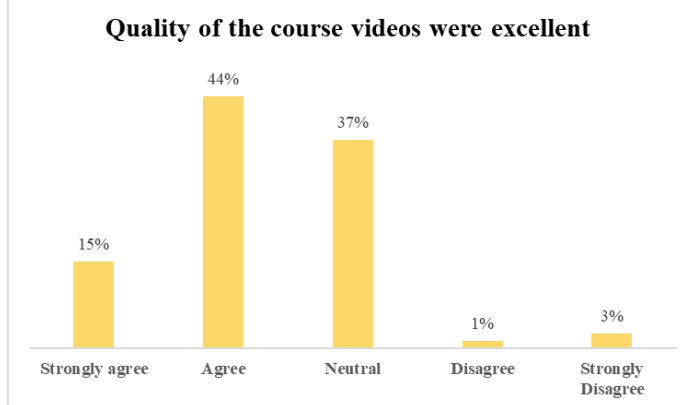

(e)

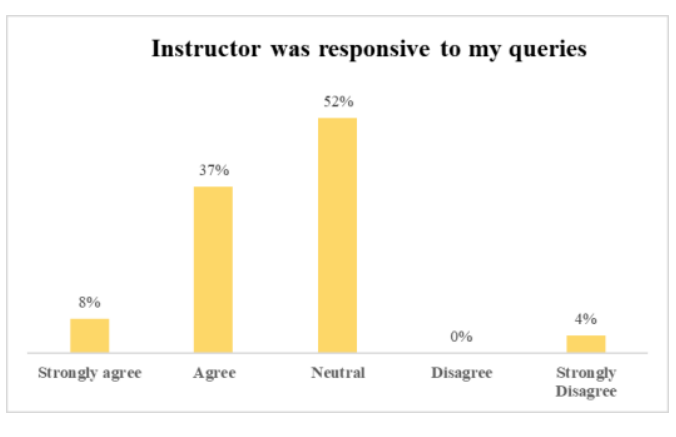

(b)

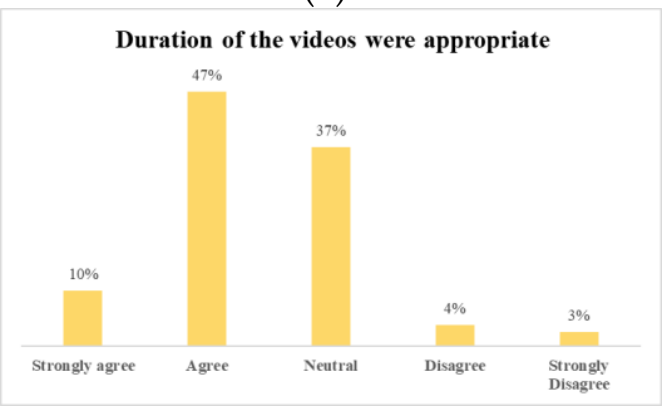

(d)

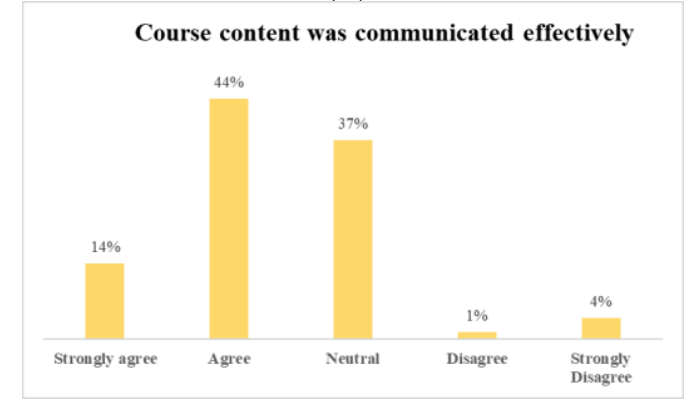

(f)

Figure 9. Motivational factors to complete MOOC

\subsubsection{RQ3: What are the reasons of dropping MOOC?}

Figure 10 shows the different reasons for dropping MOOCs. 38\% of the participants commented that they were not able to meet the deadline, $14 \%$ commented on other reasons such as boring, insufficient time, the course was too slow, got enrolled in many courses, lost interest, distraction, financial issues, 
busy schedule, etc. $14 \%$ responded that instructor language was difficult to follow, $14 \%$ responded that they were not able to understand the course content, $10 \%$ commented about problems/issues related to software installation, and $10 \%$ dropped the course because they were not able to solve the assignments.

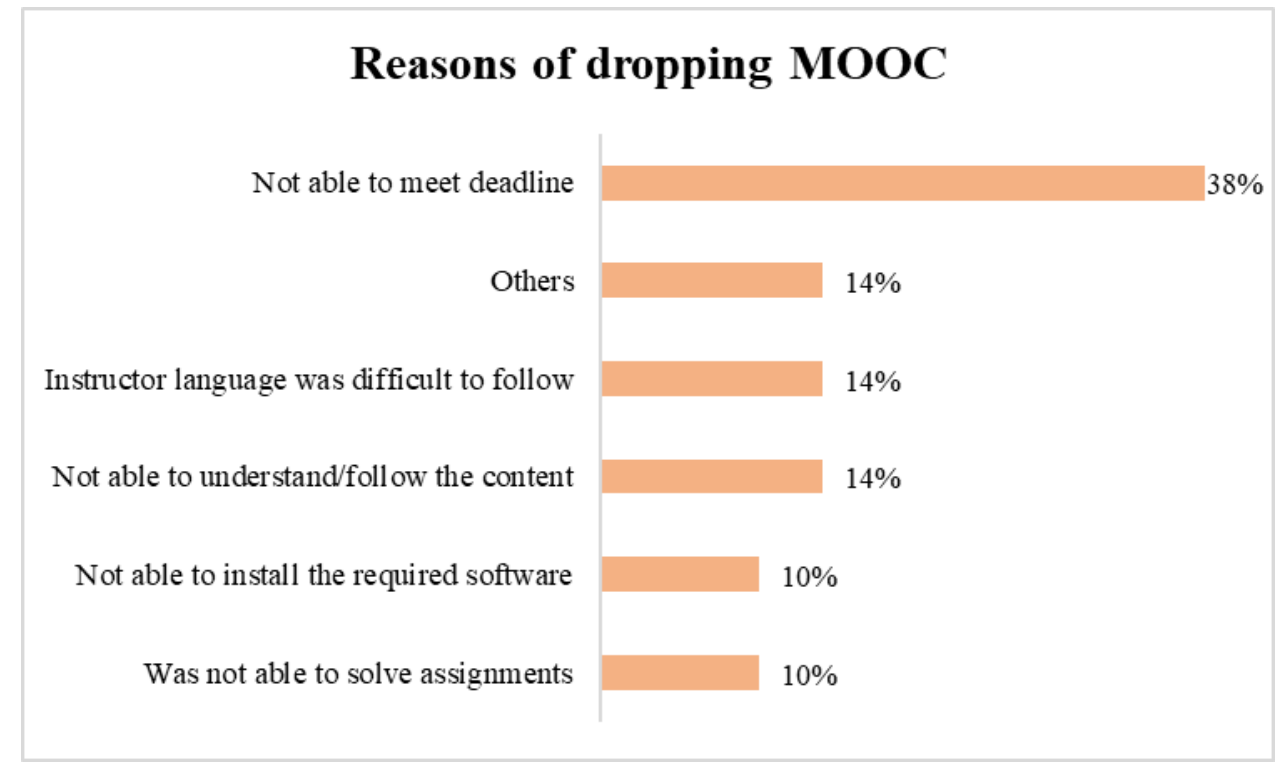

Figure 10. Reasons of dropping MOOC

4.2.4 RQ4: What are the strengths and limitations of MOOCs?

Figure 11 shows the strengths of MOOC, commented multiple times by the respondents. A wide range of courses resulted as the top 1 strength of MOOC with $27 \%$ followed by Convenient (23\%), Improves skills and knowledge (19\%), Flexible timings (15\%), Easy Access (13\%), and Free courses (3\%).

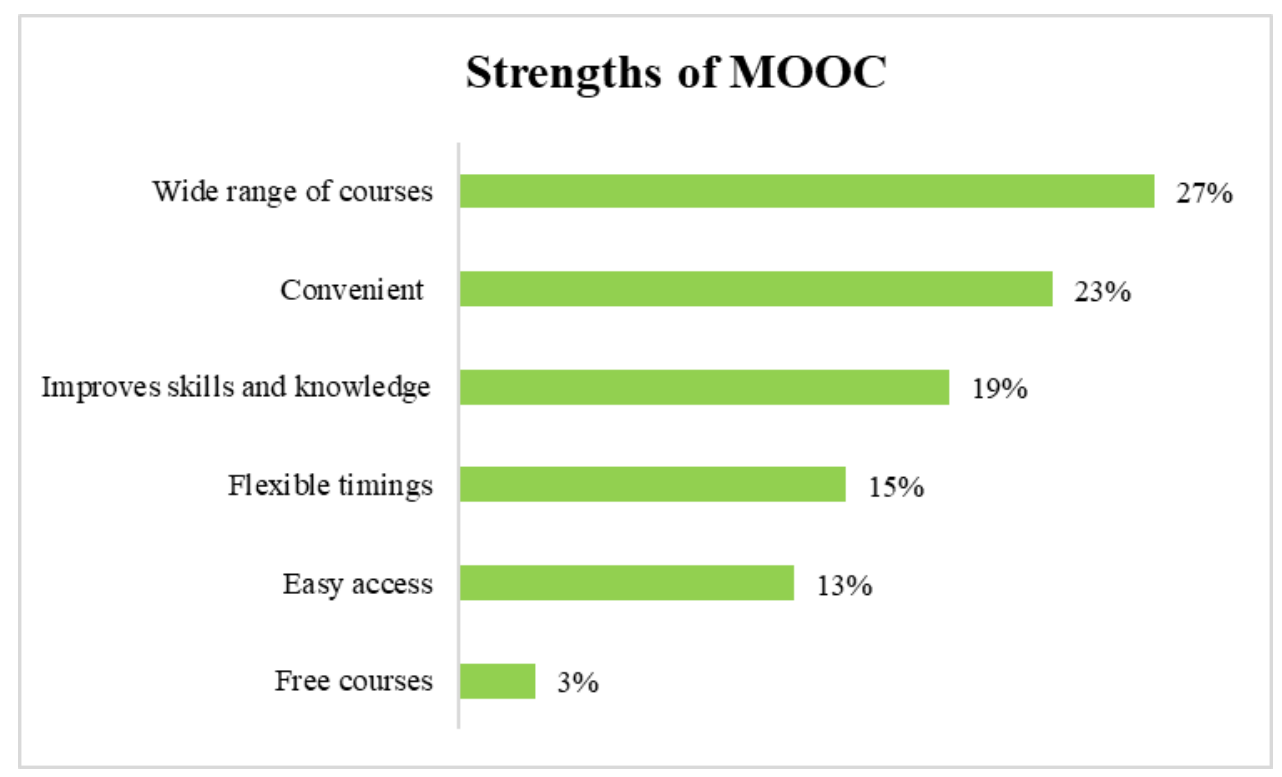

Figure 11. Strengths of MOOC 
Figure 12 shows the different limitations of MOOC as suggested multiple times by the respondents. Distraction topped the list $(20 \%)$, followed by complex assessments $(14 \%)$, tight deadlines $(14 \%)$, certification only for paid courses $(12 \%)$, complex course content $(12 \%)$, lack of motivation $(9 \%)$, less hands-on sessions $(8 \%)$, non-acceptance of MOOC as a traditional course $(6 \%)$, internet issues $(4 \%)$, and difficulty in searching authorized courses $(1 \%)$.

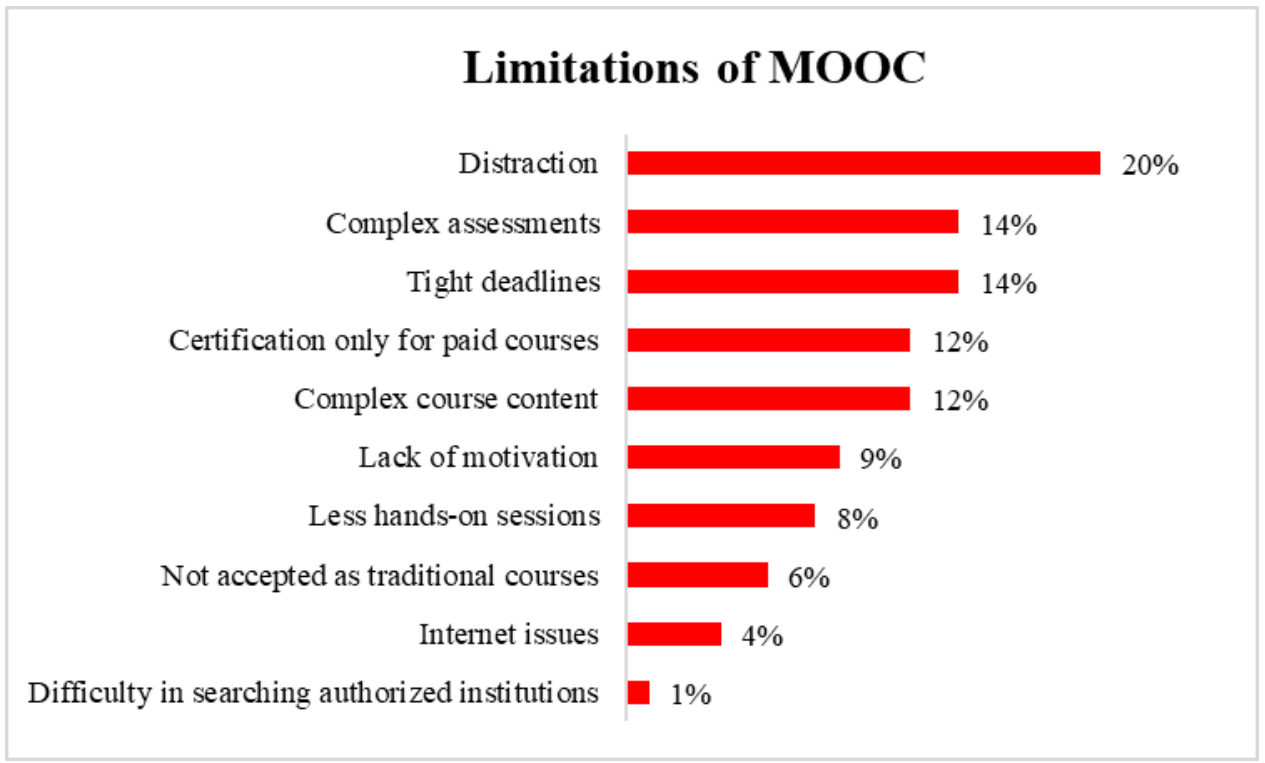

Fig.12. Limitations of MOOC

\section{Discussion}

The first research question in this study sought to determine the motivational factors of MOOC enrollment. Unfortunately, the literature on the motivating elements that drive MOOC enrolment is limited. Therefore, the findings of the RQ1 are not exactly matching with the results of previous studies ("Postgraduate Students" Motivation for MOOC Enrollment," 2019), which have indicated that the majority of the students enrolled for MOOC because prestigious universities offer it. Other factors reported were the desire to learn, and the course was not offered at other institutions. Our findings, however, are consistent with those of (Milligan \& Littlejohn, 2017; Petronzi \& Hadi, 2016), who found that one of the reasons for MOOC enrollment is to broaden one's skills to be more effective at work and for professional growth. Professional growth was likewise identified as the most important motivator for MOOC enrolment in our research.

A majority of our respondents were employed (91\%), flexible timing of MOOC received the second-highest percentage as the motivational factor. This result may be explained by the fact that MOOCs allow learners to complete them at their own pace, irrespective of the fixed schedules. The results are also partially consistent with the study of (Douglas et al., 2020), which reported flexibility and the unlimited timeframe are motivating factors for enrolling in a MOOC. The majority of the MOOC providers offer courses for free, except a few which require the learners to pay to attend exams and to receive the certificate. So, this motivated $17 \%$ of the respondents. An online completion certificate is offered by 
MOOC courses for learners who complete the course modules successfully. As a result, $14 \%$ of respondents believe it is a motivating element. This result contradicts the findings of (Knöös \& Rääf, 2021), which revealed that receiving the certificate was not a significant motivator. Even though the courses require payment, $12 \%$ of respondents believe they are affordable. World-class institutions provide a variety of fundamental courses that anyone with a desire to study can enroll in. As a result, $7 \%$ of respondents stated that they registered in a MOOC since there are no prerequisites. This finding is in line with (Bingol et al., 2020), who discovered that affordability, openness to all, and the lack of prerequisites all motivated participants to enroll in and complete the course. Our findings may be interpreted with caution as we are unclear about the type of MOOC such participants enrolled in. Participants in the study were those who registered in any MOOC course. Employers may not consider MOOC certificates for job promotions, even though they improve the learner's skills. So, only $1 \%$ of respondents said they took MOOC to get a promotion. As shown in Figure 5, the gender-based analysis of the motivational elements reveals that females suggested all the motivational factors more than males.

The second research question investigates the motivational factors that enable a learner to complete MOOC. Figure 9 presents the results obtained regarding the motivational factors to continue MOOC. As can be seen from the figure, the largest number of respondents (59\%) agreed to the fact that the "Quality of the course videos was excellent". It was followed by the factors "Course content was communicated effectively" and "Directions of the instructor were legible and easy to follow" with 58\% agreement. "Duration of the videos were appropriate" scored the next highest majority of $57 \%$ followed by "Instructor was responsive to my queries" with $45 \%$ and "Instructor provided helpful and timely feedback" scored the least percentage of $43 \%$. It is somewhat surprising that, of all the motivational factors provided in the questionnaire, many respondents opted "Neutral". It is difficult to explain this result, but it denotes a state of confusion of the respondent. One probable explanation for this is that many of the respondents enrolled in/completed multiple MOOCs, therefore their experiences will vary, leading to a mixed agreement mode.

Our results related to the second research question reflect those of (Kumar \& Kumar, 2020) who also found that course content and course delivery significantly affect the overall satisfaction level from the MOOCs. As per the research of (Bingol et al., 2020), the factors for successful course completion, were identified as the instructor, course design, personal factors, and affordability/clarity. As per the research of (Hone \& El Said, 2016), MOOC retention was found to be significantly influenced by course content and interaction with the instructor whereas the study of (Zhang et al., 2019) reported that the completion rate of MOOCs rises when they are offered by universities with solid academic quality.

The third question in this research was to investigate the reasons for dropping MOOCs. According to several surveys, the most prevalent cause for dropping out is a lack of time. As per our findings, the topmost reason for dropout commented by the respondents is not able to meet a deadline (38\%) and the next 
reason is the difficulty in understanding the course content (14\%). These results are consistent with the findings of (Knöös \& Rääf, 2021) which found that some of the reasons for dropout as lack of time and the difficulty of the course. Further, $14 \%$ of our respondents said that it was difficult to grasp the instructor's English, and difficult to grasp the course content, and $10 \%$ of the respondents commented "failure to complete assignments" as the reason to drop MOOC. These findings are consistent with the study findings of Khanra et al. (2020) which reported difficulty to understand complex topics, lengthy and unnecessary assignments, and accent of the Instructors as a few factors behind dropping out from MOOCs.

Concerning the fourth research question, two open questions were included in the questionnaire to collect the comments about the strengths and limitations of MOOC. Figure 11 and Figure 12 presents the results. In accordance with our results, the existing literature (Bates, 2015; Mehta, 2020; Pappas, 2015; Srikanth, 2020; ) has also stated free of cost, availability of top university courses, a wide range of courses, convenience, improve skills and professional knowledge, flexible timings as the advantages of MOOC.

A mixed set of responses was received from the participants regarding the limitations of MOOCs; distraction; difficulty to find authorized MOOCs courses; non-acceptance of MOOCs certificate by the employer; not much value for the online courses in the market; course content not tailored for a MOOC setting; lack of good Internet connection; lack of essential IT knowledge; difficulty to find high-valued courses; too many deadlines; increase in screen time; commitment required; a certificate is obtained only for paid courses; limited practical applications; online network issues; lack of motivation; few hands-on or practical activities; less personal engagements; not a replacement of format education; time limits; etc. Among the different answers, distraction, complex assessments, and tight deadlines were found to be the top three drawbacks mentioned by the participants.

\section{Conclusion}

Prior literature is mainly focused on the importance of MOOC in the case of learners' motivations and dropping out of MOOC courses. We reported systematic analysis of the relevance of MOOC course, the interest of students, the content of classes, faculty involvement, and reasons for adopting MOOC courses and dropping out in the middle of the system using real-time data. This study aimed to investigate the characteristics that drive learners to enroll in and complete MOOCs, the elements that cause learners to drop out of the course, and the benefits and drawbacks of MOOCs. Four significant criteria, such as professional advancement, flexible time, no cost, and the possibility of gaining certification, directly influenced student enrollment in MOOCs. Good-quality course videos, straightforward tutor directions, good course delivery, and meaningful instructor comments were among the motivational elements identified in this study that resulted in successful MOOC completion. On the other hand, the inability to meet the deadline, the instructor's language, challenging assignments, and difficulties in understanding the course topic were found to be the most common causes for dropout. 
The study's conclusions have significant consequences for the effective delivery of MOOCs and the results extend to the process of planning and creating new MOOCs by expanding our knowledge of MOOC learners' interests. The outcomes of our study are expected to aid MOOC providers in creating more productive, efficient, and engaging learning environments. This study may also serve as a foundation for future research on the elements that most affect learners' decisions to enroll in and continue MOOCs and the causes why learners drop out of MOOCs. However, this study has limitations, such as small sample size. More research into learner motivations and MOOC enrollment, completion, and dropout across specific MOOCs or MOOCs offered by multiple providers and in different topic areas can be undertaken in the future.

\section{Funding}

The research leading to these results has received funding from the Research Council (TRC) of the Sultanate of Oman under the Block Funding Program $\mathrm{BFP} / \mathrm{RGP} / \mathrm{ICT} / 19 / 283$.

\section{References}

Albelbisi, N. A., Al-Adwan, A. S., \& Habibi, A. (2021). Impact of Quality Antecedents On Satisfaction Toward MOOC. Turkish Online Journal of Distance Education, 22(2), 164-175.

Aldowah, H., Al-Samarraie, H., Alzahrani, A. I., \& Alalwan, N. (2020). Factors affecting student dropout in MOOCs: A cause and effect decision-making model. Journal of Computing in Higher Education, 32(2), 429-454. https://doi.org/10.1007/s12528-019-09241-y

Alraimi, K. M., Zo, H., \& Ciganek, A. P. (2015). Understanding the MOOCs continuance: The role of openness and reputation. Computers \& Education, 80, 28-38. https:// doi.org/10.1016/j.compedu.2014.08.006

Bates, A. W. . (2015). 5.4 Strengths and weaknesses of MOOCs. Retrieved from https://opentextbc.ca/teachinginadigitalage/chapter/section-7-5-strengthsand-weaknesses-of-moocs/

Bingol, I., Kursun, E., \& Kayaduman, H. (2020). Factors for Success and Course Completion in Massive Open Online Courses through the Lens of Participant Types. Open Praxis, 12(2), 223. https://doi.org/10.5944/openpraxis.12.2.1067

Douglas, K. A., Merzdorf, H. E., Hicks, N. M., Sarfraz, M. I., \& Bermel, P. (2020). Challenges to assessing motivation in MOOC learners: An application of an argument-based approach. Computers \& Education, 150, 103829. https://doi.org/10.1016/j.compedu.2020.103829

Hone, K. S., \& El Said, G. R. (2016). Exploring the factors affecting MOOC retention: A survey study. Computers \& Education, 98, 157-168. https:// doi.org/10.1016/j.compedu.2016.03.016

Jais, J., Chen, S.D., R Rahim, R.E.A., Din, N.M. (2019), Postgraduate Students"e Motivation for MOOC Enrollment. International Journal of Engineering and Advanced Technology, -9(1), 1763-1765. https://doi.org/10.35940/ijeat.A2698.109119

Khanra, S., Budankayala, M., \& Doddi, S. T. (2020). Barriers Towards the Adoption of Digital Learning Platforms. Academy of Marketing Studies Journal. Retrieved from https://www.abacademies.org/abstract/barriers-towards-the-adoption-ofdigital-learning-platforms-9530.html 
Kim, D., Jung, E., Yoon, M., Chang, Y., Park, S., Kim, D., \& Demir, F. (2021). Exploring the structural relationships between course design factors, learner commitment, self-directed learning, and intentions for further learning in a self-paced MOOC. $\begin{array}{llll}\text { Computers } & \mathcal{E} & \text { Education, } & 104171 .\end{array}$ https://doi.org/10.1016/j.compedu.2021.104171

Knöös, J., \& Rääf, S. A. (2021). Sentiment Analysis of MOOC learner reviews: What motivates learners to complete a course? (Dissertation) http:/ / urn.kb.se/resolve?urn=urn:nbn:se:lnu:diva-105919

Kumar, P., \& Kumar, N. (2020). A study of learner's satisfaction from MOOCs through a mediation model. Procedia Computer Science, 173, 354-363. https:// doi.org/10.1016/j.procs.2020.06.041

Mehta, N. (2020). What Is MOOC-Based Learning? Retrieved from https://elearningindustry.com/mooc-based-learning-advantages-anddisadvantages

Milligan, C., \& Littlejohn, A. (2017). Why Study on a MOOC? The Motives of Students and Professionals. The International Review of Research in Open and Distributed Learning, 18(2). https:// doi.org/10.19173/irrodl.v18i2.3033

Moore, R. L., \& Wang, C. (2021). Influence of learner motivational dispositions on MOOC completion. Journal of Computing in Higher Education, 33(1), 121-134. https://doi.org/10.1007/s12528-020-09258-8

Panagiotakopoulos, T., Kotsiantis, S., Kostopoulos, G., Iatrellis, O., \& Kameas, A. (2021). Early Dropout Prediction in MOOCs through Supervised Learning and $\begin{array}{llll}\text { Hyperparameter Optimization. } \quad \text { Electronics, } & 10(14), \quad 1701 .\end{array}$ https:// doi.org/10.3390/electronics10141701

Pappas, C. (2015). 6 Benefits Of Using MOOCs For Corporate Training. Retrieved from https:/ / elearningindustry.com/6-benefits-of-using-moocs-for-corporatetraining

Petronzi, D., \& Hadi, M. (2016). Exploring the Factors Associated with MOOC Engagement, Retention and the Wider Benefits for Learners. European Journal of Open, Distance and E-Learning, 19(2), 112-129. https://doi.org/10.1515/eurodl2016-0011

Rawat, S., Kumar, D., Khattri, C., \& Kumar, P. (2021). Machine Learning Classification Algorithms for Systematic Analysis to Understand Learners Drop out of MOOCs courses [Preprint]. https://doi.org/10.21203/rs.3.rs-491528/v1

Shrader, S., Wu, M., Owens-Nicholson, D., \& Santa Ana, K. (2016). Massive Open Online Courses (MOOCs): Participant Activity, Demographics, and Satisfaction. Online Learning, 20(2). https:/ / doi.org/10.24059/olj.v20i2.596

Srikanth, M. (2020). Advantages $\mathcal{E}$ Disadvantages of MOOCs for Learning. https:/ / www.infoprolearning.com/blog/advantages-and-disadvantages-ofmoocs-massive-open-online-courses-for-learning/

Yesil, D. (2014). How To Motivate MOOC Learners. Retrieved from https://elearningindustry.com/motivate-mooc-learners

Zhang, Q., Bonafini, F. C., Lockee, B. B., Jablokow, K. W., \& Hu, X. (2019). Exploring Demographics and Students' Motivation as Predictors of Completion of a Massive Open Online Course. The International Review of Research in Open and Distributed Learning, 20(2). https:/ / doi.org/10.19173/irrodl.v20i2.3730 